\title{
PW01-010 - The effect of pregnancy on disease course in FMF
}

\author{
T Eviatar, N Zaks, OL Kukuy, A Livneh*, M Lidar \\ From 7th Congress of International Society of Systemic Auto-Inflammatory Diseases (ISSAID) \\ Lausanne, Switerland. 22-26 May 2013
}

\section{Introduction}

FMF is the most common of the hereditary periodic fever syndromes. It usually begins in the first two decades of life, and as such, has a significant impact on women in their reproductive years. To date, only one retrospective study, investigating the course of FMF in pregnancy, has been published.

\section{Objectives}

To examine the course of disease in FMF patients, while pregnant, and to evaluate the association of pregnancy with attack frequency and severity.

\section{Methods}

All pregnant FMF patients treated at the FMF clinic of the Sheba Medical Center from May 2010 onwards, consenting to participate in this observational study, were studied prospectively for the occurrence of attacks. Attacks were recorded by patients in diaries provided on enrollment and relied by phone to a study coordinator on a monthly telephone call or on a pre-specified physician visit, whichever occurred first. In addition to noting attack occurrence, patients were instructed to record attack severity (on a 1-10 scale), attack location, duration, medications taken during the attack, colchicine dose prior to and during the attack, as well as ancillary signs and symptoms related to their FMF such as the occurrence of exertional leg pain.

\section{Results}

We present results of 28 pregnancies in 24 patients. Average attack rate remained unchanged throughout the pregnancy and the 9 month follow-up period post delivery (Average attack rates per 3 months, in the year before pregnancy vs. $1^{\text {st }}, 2^{\text {nd }}$ and $3^{\text {rd }}$ trimester of pregnancy as well as the 9 months post delivery are $2.4295 \% \mathrm{CI}$ : $1.3-$ 6.1, 2.4 95\%CI:0.8-4, 2.2 95\%CI:0.9-2.5, 2.2 95\%CI:1.1-4.3 and $1.9495 \% \mathrm{CI} 0.2-3.6$, respectively).That being, an amelioration in attack rate was experienced in $25 \%$ of the pregnancies including $10.7 \%$ of pregnancies in which attack rate decreased by more than $80 \%$ compared to the pre-pregnancy value. Conversely, in $28.5 \%$ of pregnancies patients experienced more frequent attacks. No significant changes in attack severity or location, nor in colchicine dose were noted. Early delivery was indicated in about $10 \%$ of cases including a single patient with pre-existing proteinuria, and increasing urinary protein levels during the $3^{\text {rd }}$ trimester. Pregnancy outcome was favorable in all cases.

\section{Conclusion}

Pregnancy in FMF is safe for patients and their offspring. Odds for amelioration, worsening or endurance of prior course are similarly shared.

\section{Disclosure of interest}

None declared.

Published: 8 November 2013

doi:10.1186/1546-0096-11-S1-A63

Cite this article as: Eviatar et al:: PW01-010 - The effect of pregnancy on disease course in FMF. Pediatric Rheumatology 2013 11(Suppl 1):A63.

\footnotetext{
Sheba Medical Center, Ramat Gan, Israel
}

(c) 2013 Eviatar et al; licensee BioMed Central Ltd. This is an Open Access article distributed under the terms of the Creative Commons B. Wed Central Attribution License (http://creativecommons.org/licenses/by/2.0), which permits unrestricted use, distribution, and reproduction in any medium, provided the original work is properly cited. 